\title{
Language Acquisition: The Role of Grammar Acquisition and Instruction in Second Language Teaching and Learning
}

\author{
Mark Anthony Reyes Aguion ${ }^{1} \square$ Jeanelle Anne B. Baraña ${ }^{2}$, CZARLAINE VALDERRAMA ${ }^{3}$, Adriane Y. De La \\ Cruz $^{4}$ and Ramil G. Ilustre ${ }^{5}$ \\ ${ }^{1234}$ Bulacan State University, City of Malolos, Philippines \\ ${ }^{5}$ Professional Lecturer of English, Bulacan State University, City of Malolos, Philippines
}

$\square$ Corresponding Author: Mark Anthony Reyes Aguion, E-mail: markanthony.aguion.r@bulsu.edu.ph

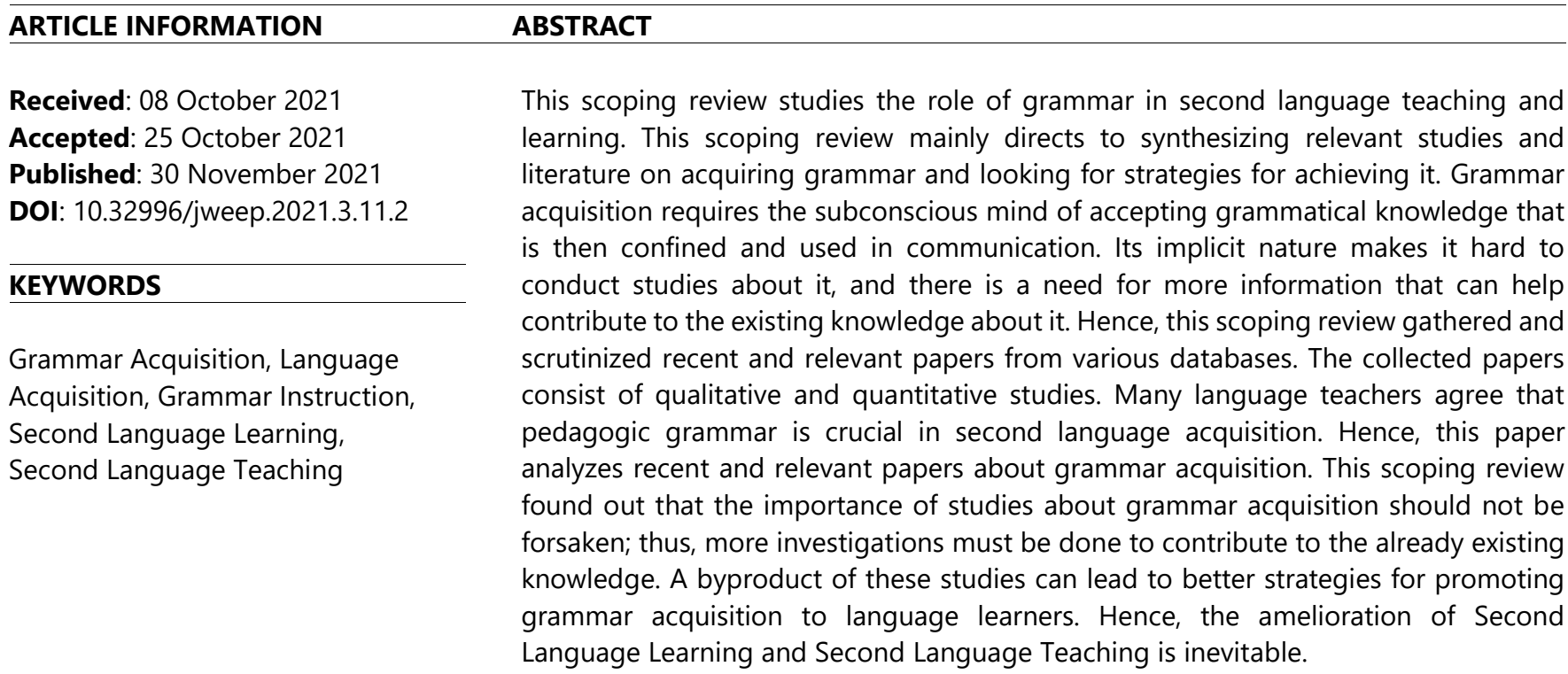

\section{Introduction}

Language is a complicated structure. It includes many matters that are hard to be conceptualized. Filho and Queriquelli (2017) stated that language, due to its four subsystems comprisal - namely the Discourse, Grammar, Lexicon, and Semantics, is pondered as a complex system. Grammar alone is a big world-many have been debating what grammar is. Grammar is an organization of rules and exceptions that disclose the language's meaning (Eunson, 2020). This definition then leads to an argument about descriptive and prescriptive grammar.

"The ongoing debate about the usage, usefulness, and purposes of prescriptive and descriptive grammars has been continuing since the early history of writing, literacy, and attempts at language standardization." (Hinkel, 2018)

With that being mentioned, many may have been confused about what grammar is. The acquisition and learning of language are two different things. According to Zaščerinska (2010), the synergy between language acquisition and language learning can develop systematic perspectives externally and internally. Learning a language differs from acquiring a language. Both are important in enriching people's knowledge about languages. In an article written by Andrew Nunn in 2016 titled The Importance Of Language Acquisition, language acquisition averts the mentality of "us vs. them" and opens more cultural understanding and cultural mindset. In addition, Nassaji (2017) refers to grammar acquisition when a person acquires the structures and the rules of a language and when that person can use what he/she acquires in a communicative context. Making studies about grammar

Copyright: (c) 2021 the Author(s). This article is an open access article distributed under the terms and conditions of the Creative Commons Attribution (CC-BY) 4.0 license (https://creativecommons.org/licenses/by/4.0/). Published by Al-Kindi Centre for Research and Development, London, United Kingdom. 
acquisition is very important, for it also helps to make the teaching of grammar more effective in the classroom. However, this point must have more empirical research.

Unfortunately, even though studies about language learning have become more prevalent ever since the 1970s, grammar acquisition, compared to other skills in language, has not been given as much notice (Anderson, 2005, Pawlak, 2009, as cited in Supakorn, Feng \& Limmun, 2018). More so, Park and Lee (2007) deliberately stated that investigations about grammar strategies have much been brushed aside in the research literature.

Wagner and Wulf (2016) quoted that pedagogic grammar is a crucial component of second language acquisition. In this scoping research, the researchers intend to systematically study the role of grammar in second language teaching and learning.

Arksey and O'Malley (2005) identified the four reasons why researchers should write a scoping review. The researchers also aim to discover the scope and nature of the grammar acquisition, learn and write a full systematic review about the grammar acquisition, synthesize the findings of the studies the researchers have collected, and find out more about the research gaps that can help the future researchers about grammar acquisition.

What is the role of grammar in second teaching and learning? This is often a matter that has been asked and debated by several language teachers and researchers for many years. The role of grammar within the foreign language classroom is also compared to an apparatus that swings back and forth, conversely swaying between extremes. Traditionally, grammar played a central role in teaching, dominating the classroom, and grammar was typically the sole activity practiced in foreign language classrooms. On one extreme, researchers hypothesize that grammar teaching and language pedagogy square measure nearly similar. There square measure people who advocate for the overall communicative approach on the opposite hand. During this approach, the sole activity within the schoolroom is to speak a couple of topics or to browse writing and so discuss it. There is no formal grammatical instruction during this technique. In several cases, what has exhausted one category does not give what has been seen within the next category.

\section{Literature Review \\ 2.1 Language Acquisition}

Acquiring a language is one of the central topics in science. Each psychological feature theory has tried to elucidate it; most likely, no alternative topic has aroused such conflict. Obtaining a new language is the quintessentially human trait: all traditional humans speak, no bloodless animal will. The local area network gauge is the main vehicle we all know regarding alternative people's thoughts, and the two should be intimately connected. Whenever we tend to speak, we tend to are revealing one thing regarding language. Therefore, the facts of language structure are simple to come back by; this information hints at a system of extraordinary quality. Still, learning a primary language several things each kid will succeed in an exceedingly matter of a few years and while not the requirement for formal lessons. With language, therefore, getting ready to the core of what it suggests to be human, it is not shocking that children's acquisition of language has received such a lot of attention. Anyone with total views regarding the human mind would like to indicate that children's initial few steps are steps in the right direction.

Language acquisition analysis is vital for our understanding of man generally and of the kid's intellectual development in particular; it addresses important questions about man's character, queries that have generated a good deal of spirited and infrequently resentful dialogue over the centuries amongst philosophers and psychologists. Here we will briefly think about four such themes; within the course of the book, we tend to hope to indicate how they are addressed and lit by the analysis on language acquisition.

Pinker (1995) defined language as the primary vehicle that can lead to discovering one's thoughts. Pinker also mentioned that because of the unique adaptations of the human brain, language is then acquired. Barto and Saville-Troike (2017) elucidated that Second Language Acquisition or SLA is the study of a new language by a solo individual or by a group following their native language.

To fully understand language acquisition, we need to understand the origin of SLA, said by Larsen-Freeman (2018, as cited in Ellis, 2020). According to Ellis (2020), in SLA, studies have already addressed these five (5) phases in aspects about L2 acquisition: [1] 'Making a Start' - in which it focused on the order and sequence of acquisition; [2] 'Expansion Period' - Language transfer, Universal Grammar, Second Language Pragmatics, and Input and Interaction were talked about; [3] 'Cognitive Phase' - which dealt with the studies about Implicit Knowledge and Explicit Knowledge, Skill Learning Theory. Consciousness and L2 acquisition, and emergentism; [4] 'The Social Turn' - that focused on the Socialization theories and the Sociocultural Theory; and [5] 'Recent Developments' - which we are talking about the Complex Dynamic Systems Theory and the Transdisciplinary. The success of SLA studies "lies in the contribution it can make to well-established disciplines and to addressing practical problems" Ellis (2020, p. 202).

Understanding Second Language Acquisition could be a thorough and careful synthesis of current analysis in second language acquisition (SLA). Whereas typically supposed for college students taking an introductory course in SLA, Ellis comments explicitly 
on the book's importance for lecturers of second or foreign languages: "This book seeks to assist lecturers to create their theory of acquisition specific through associate examination of language-learner language and also the processes that turn out it. It has supported the conviction that lecturers are comfortable with a certain set of ideas regarding language learning" (p.2). the fact that Ellis does not expressly address himself to the implications of SLA analysis associated theory for teaching second and foreign languages must not deter language lecturers from reading this book; it is a highly intelligible account of problems in SLA that are essential to an understanding of the acquisition method. Chapter one provides a preview of the "key issues" mentioned in additional detail in resultant chapters; Ellis considers factors that are each external (e.g., situation, input) and internal (e.g., linguistic and cognitive processes) to the learner.

\subsection{Grammar Acquisition and Instruction}

The instruction in $\mathrm{L} 2$ acquisition's role has been a critical question and a theoretical issue within the field. It had been directly addressed by Long (1983) during a paper in which he bestowed the results of many classroom-based empirical studies, all addressing the question of whether or not instruction may be helpful for $L 2$ learners. In his review, he thought about eleven studies examining whether the learners receiving instruction achieved the next level of proficiency than those learners. In these eleven studies, schoolroom solely, realistic exposure solely, and schoolroom and realistic exposure were compared. Long ended that the findings indicate that instruction is helpful for adults (intermediate and advanced stages) and youngsters. It is helpful each in acquisition-rich contexts (i.e., during which learners are exposed to the target language outside the schoolroom context) and acquisition-poor environments (i.e., during which learners are exposed to the target language solely during a schoolroom context). Such edges emerge even though the means proficiency is measured. Long ended that a mix of instruction and practical exposure to the input was best conditions as instruction looks to impact the speed of and supreme success in L2 acquisition.

Incidental descriptive grammar acquisition involves learners "picking up" a grammatical feature, whereas their primary focus is on another facet of language, either message content or another language feature that's tutored directly. This text reports a study of children's incidental descriptive linguistics acquisition of 2 grammatical features-plural $-s$ and copulative be-in 2 kinds of instruction-focusing on the kind (fonf) and target forms (fonfs). The options were not directly tutored; however, opportunities for learning them occurred in schoolroom interactions. Thirty young beginner Japanese learners were divided into two teams (fonf and fonfs) and received nine recurrent lessons over five weeks. The study examined learners' acquisition of the two structures as measured by tests and wanted explanations for the ends up in terms of the variations in interactions that arose within the two tutorial contexts and, particularly, opportunities for about to the grammatical options in these interactions. The kids within the fonf schoolroom incontestable acquisition of plural -s however not of copulative be. Neither structure was nonheritable by the kids within the fonfs schoolroom. Analysis of the schoolroom interactions shows a purposeful way to attend to plural $-\mathrm{s}$ (but not copulative be) solely within the fonf schoolroom.

The previous language data of learners for whom the target language is not the 1st foreign language poses a unique beginning learning scenario that should advantage education attention. The current paper seeks to contribute to whether education issues are created regarding the role of previous language data on the far side tutored $L 2$ synchronic linguistics acquisition. Moreover, it fills a significant gap increasing the limited existing education choices that instructors have at their disposal once it involves teaching in lecture rooms wherever one foreign language is at the same time chronologically 1 st to some and second to othersbeginning with (combinations of) existing theoretical accounts and associated education aspects (such as express info, negative proof, metalinguistic explanations, synchronic linguistics consciousness-raising, and input enhancement), a recently developed technique (Hahn \& Angelovska, 2017) is mentioned. The tactic acknowledges the 3 phases of input, apply and output and is applicable in tutored L2 synchronic linguistics acquisition and on the far side.

Many researchers wanted to prove which strategy could be better be used in the classroom setting to promote the excellent acquisition of a language. Many of these studies have been being widely used in an English classroom, and the aim is to provide much better-quality education to L2 learners.

Ni'mah (2020) stated that some learners learn a new language quickly and faster than others. In addition, some learners learn a language because of their effort, perseverance, and determination. Nevertheless, there are still more important factors to consider why a person becomes successful in learning a language that is perforce to the learners. In a case study conducted by Ulin Ni'mah in 2020 titled CASE STUDY: THE ROLE OF LEARNING STRATEGIES, PERSONALITY, AND MOTIVATION IN THE SECOND LANGUAGE ACQUISITION: WRITING PROFICIENCY OF A SOMALIAN STUDENT, intended to study the second language acquisition of an international student from the Universitas Islam Negeri Maulana Malik Ibrahim, Malang. This study primarily focused on the three aspects: personality, motivation, and the learning strategy of the learner. This case study has proven that the learning strategies, together with the personality and the learners' motivation in general, can determine the learner's success in acquiring a second language. In addition, since learning or acquiring a new language must take action, learners are encouraged to improve themselves personally and do some beneficial activities that can contribute to their learning and acquiring a new language. In addition, the 
writing skills of the student being observed in this study had shown that he acquired various grammar rules that improved this writing skills.

In 2017, Rasuki made a study named 2. The Incidental Acquisition of English Nominal Structures by a Young EFL Learner under Comprehension-based Lessons to determine the effectivity of comprehension-based lessons in facilitating the incidental acquisition of English nominal structures by a young EFL learner. Accordingly, "input" plays a significant role in L2 acquisition. Input can be any L2-related data that learners receive inside and outside of the classroom. Nevertheless, the question is: can 'input' alone (without requiring the learners to produce an output) facilitate incidental acquisition? According to Krashen, the acquisition is to be defined as when the learners "know" L2 systems utilizing subconscious learning. Acquisition only takes place through exposure to "comprehensible input." Also, according to Krashen, learning refers to the state where the learners "know" L2 systems through conscious learning. Krashen stated that only through can learners use the L2 fluently and accurately in spontaneous speech while learning only contributes to monitoring L2 performance. Shintani and Ellis's (2010) study proved that comprehensible input promotes L2 acquisition. Interaction should be espoused. This supported Long's Interaction Hypothesis that interactionally modified input is more effective than pre-modified input condition. Rod Ellis $(2003,2009)$ stated that using "tasks" can create conditions where learners can get exposed to interactionally modified input, which is necessary for their comprehension and acquisition. Comprehension-based lessons are effective in promoting the incidental acquisition of lexical items and morphological features in the $L 2$.

However, few studies examine the efficacy of input-based tasks (comprehension-based lessons) on the incidental acquisition of L2 nominal structures by young L2 learners. Another question had been yet to be discovered in this study: Does the use of inputbased tasks operationalized through comprehension-based lessons promote the incidental acquisition of English nominal structures by a young EFL learner? If so, what are the key features arising from the use of such tasks that facilitate the learner's acquisition of the target structures? This study proved that using input-based tasks operationalized through comprehension-based lessons can promote a young EFL learner's incidental acquisition of English nominal structures. This research also is a shred of evidence that comprehension-based lessons operationalized based on the principles of input-based tasks provide opportunities for the learner to acquire "new linguistic material." In this research, the findings show that the learner has successfully shown her ability to use English nominal structures at different levels of complexity. This study has concluded that comprehension-based lessons operationalized based on the principles of input-based task instruction conducted three times effectively facilitated the acquisition of quite complex L2 structures. Using the tasks should be authentic in communicating meaning, exposure is repeated in meaningful linguistic contexts and facilitation of interactionally modified input to learners' L2 comprehension. As a result, the young learner being carried out for this investigation had noticeably acquired basic nominal structures. It is then concluded that comprehension-based lessons or input-based tasks are practical for a particular grammar point for the learner.

In 2018, Vila studied the result of role-playing acquiring a second language for children regarding their way of expressing and communicating. Vila (2018) mentioned that playing is a crucial part of a child's life, so the children's use of playing while learning a language is much more appreciated since they can manifest what is in their minds. This study concluded that role-playing among children L2 learners is effective since the subjects were observed to acquire vocabulary and some phrases used while doing the role-play. Thus, the children L2 learners are proven to be a good strategy for acquiring a new language. Moreover, role-playing for children as learners lets them experience a world that can be very meaningful to them. Most importantly, these students subjected to this study are observed to express themselves using the basic grammar rules. Therefore, role-playing can induce vocabulary acquisition for the tested learners and acquire basic grammar rules of the second language.

Some strategies may also vary from other countries. Some countries have preferred language-learning strategies. Undoubtedly, it may sound a cliché, but there is a need for more conducted studies about the strategies to learn grammar. That is why Supakorn, Feng, and Limmun (2018) conducted the study Strategies for Better Learning of English Grammar: Chinese vs. Thais aiming to explore the differences of grammar learning strategies and the context-based approach among Thai and Chinese students. Accordingly, the use of better language strategies can play an essential role in acquiring a language. Discerning the successful and unsuccessful language learning strategies can be helpful for unsuccessful language learners to improve their language learning (Rubin, 1975, as cited in Supakorn, Feng \& Limmun, 2018). This study aimed to know the strategies used by all learners - high achievers and low achievers - to study English grammar. Also, this study wanted to seek the answer to whether the high language achievers and low language achievers in China and Thailand apply the same or different grammar learning strategies, and lastly, are strategies used from China and Thailand are typically distinguishable. The investigation showed that when it comes to using the grammar learning strategies, those high language learner achievers apply it exponentially more than those of the low achievers. For the strategies being used, both the Thai and Chinese learners, regardless of their achievements in language learning, used different grammar learning strategies. Lastly, Thai students are more distinguishable between China and Thailand than Chinese students in terms of their strategy since Thais tend to be more dependent on teachers when learning grammar. Also, Thais are revealed that they handle emotional pressure better than the Chinese regarding relaxation and self-encouragement. This study concluded that though we learn the same language (English), we tend to use different grammar-learning strategies, which results 
in significant differences for the learners. Indeed, more studies and investigations are needed to unfold the differences and similarities among national preferences of different language learners that can find better strategies, and if possible, the standard approach to learning grammar.

\subsection{Universal Grammar (UG) and Second Language Acquisition (SLA)}

Many linguists are trying to answer this question: Is acquiring a second language different from acquiring the first language? Some studies are trying to get an answer to this query. Farahani, Mehrdad, and Aghar (2013) studied it and stated that for us to understand the problem entirely, the distinction between the Fundamental Difference Hypothesis by Bley-Veroman (1989) and the Fundamental Identity Hypothesis by Schwartz (1987). The former claimed that that the Second Language Acquisition (SLA) is processed in the Language Acquisition Device (LAD), but the Foreign Language Acquisition (FLA) is processed through the use of a more general problem-solving skill (general abstract problem solving). Not having direct access of the adult L2 learners to Universal Grammar (UG) is observed. They know of universals constructed through L1, and they process it using general problemsolving abilities, such as hypothesis testing, inductive and deductive reasoning, analogy, etc.

The Fundamental Identity Hypothesis professed that the L1 acquisition uses the exact language-specific mechanism as in $\mathrm{L} 2$ acquisition. The successes and mistakes in FLA development are also observed in SLA development, for they are mimicked. This study found out if the accessibility of the UG to $L 2$ learners are seen in these four different positions: [a] No Access Point (there is no such thing as UG), [b] Indirect Access Position (UG exists, but only L2 learners have indirect access to it), [c] Partial Access Position (UG exists, but L2 learners only have partial access to it), and [d] Full Access Position (second language learners have full access to UG). This study found concluding pieces of evidence for all positions; thus, more studies are needed.

On the other hand, the paper titled Universal Grammar in Second Language Acquisition: The Nature of Interlanguage Representation by Lydia White in 1998 suggested that we should not be diverted to the fact that the Universal Grammar restricts linguistic representation. White (1989) assumed that if a specific UG principle works, the availability of the UG in L2 learners can be generalized. Or vice versa. Thus, White (1989) recommended that focusing on studies about nature instead of the source can have more profuse results about the relationship of UG in SLA.

\subsection{Second Language Learning and Second Language Teaching}

Language is believed to be at the center of human life. We tend to use it to precise our love or hatred, realize our goals and more our careers, achieve creative satisfaction or simple pleasure, and hope or blaspheme. We tend to arrange our lives and remember our past; we tend to exchange concepts and experiences; we tend to kind our social and individual identities. Language is that the most original factor regarding masses. As Cicero aforementioned in fifty-five before Christ, 'The one factor during which we tend to area unit particularly superior to beasts is that we tend to speak to every different.' Some folks' area unit ready to do some or all of this in addition to one language. Knowing another language might mean: obtaining a job; an opportunity to induce educated; the ability to require a fuller half within the lifetime of one's own country or the chance to emigrate to associate other; a growth of one's literary and cultural horizons; the expression of one's policymaking or non-secular beliefs; the possibility to speak to folks on a far-off vacation. A second language affects people's careers and possible futures, their lives, and their terrible identities. In a very world wherever most, likely additional folks speak two languages than one, the acquisition and use of second languages area unit vital to the everyday lives of millions; monolinguals are getting nearly associate endangered species. Serving to folks acquire second languages additional effectively is an essential task for the 21st century.

Second language learning (SLL) is concerned with the process and study of how people acquire a second language, which is often referred to as L2 or target language, as opposed to L1 (the native language). Generally, the term second language in this context can refer to any language (also a third or fourth language) learned in addition to the native language. However, second language learning would be contrasted with a bilingual learning situation, in which a child acquires two languages simultaneously. We only speak of second language acquisition if another language is acquired after the first language.

A glance over the past century about language instruction and learning can offer a stimulating read of however varied analysis, and theories have influenced the language setup to sway to extremes, forever advocating the most straightforward methodology for teaching and learning a second language. In step with Julio Foppoli, a tutor of English and Spanish as Second Languages, grammar is the backbone of a language. He likens grammar to a railway that permits messages to induce across. Without grammar, there is no way to express one's thoughts and concepts to others. This can result from grammar providing the required structure to arrange one's message to share ideas. Since grammar plays such a vital role in communication, there is no way to doubt the importance of the controversy regarding the role of grammar within the second language classroom. Grammar mastery is not imperative; however, what is essential is that the role of grammar and the way it ought to be given within the second language classroom. For some purpose, maybe analysis and discoveries can shift the setup towards the middle and provide the most straightforward methodology and practices that mirror in integrated grammar communicative approach for instruction and 
learning. Until that point, the task for language researchers and instructors is going to be to still search and uncover what that center might appear.

\section{Methodology}

The methodology of a scoping review involves the stages of (1) identifying the research question, (2) identifying relevant studies, (3) study selection, (4) charting the data, and (5) collating, summarizing, and reporting the results (Arksey \& O'Malley, 2005). The following keywords were used to find suitable sources: language, grammar acquisition, language acquisition, grammar instruction, second language learning, second language teaching. Sources found via the analysis were derived from Google Scholar, Scientific researches, Academia, and Research Gate. The search was mainly focused on articles published in dissertations, peer-reviewed journals, and related studies about grammar acquisition in learning the second language. Google Scholar was also used to sort sources for relevance to focus on commonly cited sources, research published in journals (peer-reviewed), or collaborative research. To identify the literature to be included in this systematic review, inclusion criteria were established. Twenty articles were included according to the strategies used for second language vocabulary acquisition.

\section{Results and Discussions}

Good grammar can show good proficiency in a language. Acquisition stays longer, and it becomes a part of the improvement of one's communication skills. This scoping research has found out that there is a need for more studies to be conducted about grammar acquisition - since it is one among the aspects of second language acquisition that is often neglected, either intentionally or unintentionally - given its complicated nature. In addition, further studies can discover the strategies for better acquisition for language learners since it is imperative to improve the instruction and the approach the language teachers use in the classroom. Moreover, the investigation about the access of $L 2$ learners to Universal Grammar (UG) may be challenging; however, the findings can contribute to more discovery of the relationship between UG and SLA. Finally, schools, especially the language teachers, must focus on Second Language Learning and Second Language Teaching, for they are essential for the learners to acquire a language better. Since it is already the 21 st century, more developed methodologies should be welcomed. The learners are developing more and more, so must the concepts for Second Language Learning and Second Language Teaching.

The role and kind of grammar instruction in language acquisition with explicit relevancy EFL has been the topic of SLA analysis and discussion for many years. However, descriptive linguistics instruction has been recognized as an essential and inescapable element of acquisition and use. It is seen as valuable, if not indispensable, in the context of EFL teaching and learning.

The role of grammar acquisition in foreign language education might be a controversial one every in second language acquisition (SLA) analysis and language pedagogy and, as a result, an attainable provide of confusion to student lecturers. The teaching of grammar plays a central role in each EFL/ESL teacher's classroom.

\section{Conclusion}

The grammar of a language exists whether or not we tend to notice it or not. Language could be a set of rules as the union of words within the sentence is not dispensed through associate discretional combination but in keeping with a regulative system with any language. We aim to gift students' views on the importance of grammar in second language acquisition. It is noted that the teaching of foreign languages in favor of the event of communication skills ends up in a scarcity of students' information on grammar.

The role of grammar within the foreign language room may be a heavily debated topic within the arena of second language education. Traditionally, there are several shifts within the overall plan of grammar presentation. Historically, grammar contends an essential role in foreign language education, typically serving because of the sole activity within the room. In recent years, there has been a push for implicit grammar displays focusing additional heavily on the employment of language for communication. A review of language-learning theories and current language acquisition analysis was performed to elucidate how grammar should be instructed. A survey of language educators was conducted and discovered that educators' most popular grammar expressly and mistreatment authentic materials. Analysis shows that specific and implicit grammar instruction each has an advantage. To fit the new World-Readiness Standards of the Yankee Council on the Teaching of Foreign Languages, language instruction should emphasize the links between language, communication, and culture. Today, teaching grammar in isolation is no longer acceptable to organize students with "real-world" language skills. Thus, an eclectic approach that integrates authentic materials and a mix of explicit and implicit grammar defines 21st language teaching and learning.

\section{References}


[1] Altakhaineh, A. R. M., \& Ibrahim, M. K. (2019). The Incidental Acquisition of English Prepositions by Arabic-Speaking EFL Learners: Evidence From Al Ain University of Science and Technology. SAGE Open, 9(3), 2158244019861497.

[2] Angelovska, T. (2017). Beyond instructed L2 grammar acquisition: Theoretical insights and pedagogical considerations about the role of prior language knowledge. Retrieved from: https://www.ceeol.com/search/article-detail?id=569435

[3] Arksey H, O'Malley L. Scoping studies: Towards a Methodological Framework. Int J Soc Res Methodol. 2005; 8(1):19-32

[4] Benati, A. and Schwieter, J (2019). Pedagogical Interventions to L2 Grammar Instruction. Retrieved from: https://www.cambridge.org/core/books/abs/cambridge-handbook-of-language-learning/pedagogical-interventions-to-I2-grammarinstruction/1D1D0934435AC9113BEEE26D60C5DCBD

[5] Buyl, A and Housen, A. (2015). Developmental stages in receptive grammar acquisition: A Processability Theory account. Retrieved from: https://journals.sagepub.com/doi/abs/10.1177/0267658315585905

[6] Dekeyser, R and Botana, G. (2015). The Effectiveness of Processing Instruction in L2 Grammar Acquisition: A Narrative Review. Retrieved from: https://academic.oup.com/applij/article-abstract/36/3/290/2422464

[7] Ellis, R. (2021). A short history of SLA: Where have we come from and where are we going? Language Teaching, 54(2), 190-205. doi:10.1017/S0261444820000038

[8] Eunson, B. (2020). English Grammar- A Critical Approach. Retrieved from: https://www.researchgate.net/publication/341370223_English_Grammar-_A_Critical_Approach

[9] Farahani, A, Gholami M, A \& Ahghar, M. (2014). Access to Universal Grammar in Adult Second Language Acquisition. Procedia - Social and Behavioral Sciences. 136. 298-301. 10.1016/j.sbspro.2014.05.332.

[10] Fazion F, M \& Queriquelli, L H. (2017). Modeling the Complexity of Language As a Two-Mode Network. SSRN Electronic Journal. $10.2139 /$ ssrn.2979319.

[11] Graus, J. and Coppen, P. (2015). Student-teacher beliefs on grammar instruction. Retrieved from: https://journals.sagepub.com/doi/abs/10.1177/1362168815603237

[12] Grit, V. (2018). EFFECTIVENESS OF GRAMMAR INSTRUCTION IN SECOND LANGUAGE ACQUISITION. Retrieved from: https://d1wqtxts1xzle7.cloudfront.net/64371623/Grit\%20-\%202018\%20\%20Effectiveness\%20of\%20grammar\%20instruction\%20in\%20L2\%20acquisition.pdf?1599471483=\&response-content-disposition

[13] Hinkel, E. (2018). Descriptive versus prescriptive grammar. The TESOL Encyclopedia of English Language Teaching, 1, 1-6. Retrieved from: http://208.106.168.105/downloads/Descriptive\%20v\%20Prescriptive.pdf

[14] Jin. L. (2020). Depth-Bounded Statistical PCFG Induction as a Model of Human Grammar Acquisition. Retrieved from: https://direct.mit.edu/coli/article/47/1/181/97336/Depth-Bounded-Statistical-PCFG-Induction-as-a

[15] Li, S. (2015). The Associations Between Language Aptitude and Second Language Grammar Acquisition: A Meta-Analytic Review of Five Decades of Research. Retrieved from: https://academic.oup.com/applij/article/36/3/385/2422456?login=true

[16] López V, C. (2018). How to role-play affects pre-schoolers second language acquisition: Communicative strategies in a P5 class in a school in Osona.

[17] Macwhinney, B. (2015). The acquisition of grammar. Retrieved from: https://www.researchgate.net/publication/234828622_The_acquisition_of_grammar

[18] Nagaratnam, R. (2020). Attitudes towards EFL grammar instruction. Retrieved from: https://www.researchgate.net/profile/Ramani-PerurNagaratnam-2/publication/299598468_Attitudes_towards_EFL_grammar_instruction/links/5fabce16458515078107d4a4/Attitudes-towardsEFL-grammar-instruction.pdf

[19] Nassaji, H. (2017). Grammar Acquisition. The Routledge Handbook of Instructed Second Language Acquisition. pp222

[20] Ni'mah, U. (2020). Case study: The role of learning strategies, personality, and motivation in the second language acquisition: writing proficiency of a Somalian student. Journal of English for Academic and Specific Purposes, 3(1), 43-55.

[21] Nunn, A. (2016). The Importance of Language Acquisition. Odyssey: Politics and Activism. Retrieved from: https://www.theodysseyonline.com/the-importance-language-acquisition

[22] Nutta, J. (2016). Is Computer-Based Grammar Instruction as Effective as Teacher-Directed Grammar Instruction for Teaching L2 Structures? Retrieved from: https://www.jstor.org/stable/24147822

[23] Pinker, S. (1995). Language Acquisition. An Invitation to Cognitive Science: Language. https://books.google.com.ph/books?hl=en\&lr=\&id=qatYCG5T4x4C\&oi=fnd\&pg=PA135\&dq=definition+of+language+acquisition\&ots=W 6J5Xy3E2z\&sig=wmct|E9i6V8KnyZzabU5MOfm9iA\&redir_esc=y\#v=onepage\&q=definition\%20of\%20language $\% 20$ acquisition\& $\mathrm{f}=\mathrm{false}$

[24] Qureshi, M. (2016). A meta-analysis: Age and second language grammar acquisition. Retrieved from: https://www.sciencedirect.com/science/article/abs/pii/S0346251X16300471

[25] Rasuki, M. (2017). The Incidental Acquisition of English Nominal Structures by a Young EFL Learner under Comprehension-based Lessons. International Journal of Applied Linguistics and English Literature, 6(4), 45-51. Retrieved from: doi:http://dx.doi.org/10.7575/aiac.ijalel.v.6n.4p.45

[26] Saville-Troike, M., \& Barto, K. (2017). Introducing second language acquisition. Cambridge University Press.

[27] Shintani, N. (2014). The Incidental Grammar Acquisition in Focus on Form and Focus on Forms Instruction for Young Beginner Learners. Retrieved from: https://doi.org/10.1002/tesq.166

[28] Shintani, N. (2015). The Effectiveness of Processing Instruction and Production-based Instruction on L2 Grammar Acquisition: A MetaAnalysis. Retrieved from: https://academic.oup.com/applij/article-abstract/36/3/306/2422461

[29] Shintani, N. (2017). Input-based tasks and the acquisition of vocabulary and grammar: A process-product study. Retrieved from: https://journals.sagepub.com/doi/abs/10.1177/1362168811431378

[30] Sun, G. (2016). The acquisition of English articles by second language learners: The sequence, differences, and difficulties. SAGE Open, 6(1), 2158244016635716

[31] Supakorn, P., Feng, M., \& Limmun, W. (2018). Strategies for Better Learning of English Grammar: Chinese vs. Thais. English Language Teaching, 11(3), 24-39. 
[32] Wagner, J. \& Wulf, D. (2016). Understanding Written Corrective Feedback in Second-Language Grammar Acquisition. Journal of Education and Learning. https://files.eric.ed.gov/fulltext/EJ1118731.pdf

[33] White, L. (1989). UNIVERSAL GRAMMAR IN SECOND LANGUAGE ACQUISITION: THE NATURE OF INTERLANGUAGE REPRESENTATION. McGill University. http://nflrc.hawaii.edu/NetWorks/NW09/white.pdf

[34] Zaščerinska, J. (2015). LANGUAGE ACQUISITION AND LANGUAGE LEARNING: DEVELOPING THE SYSTEM OF EXTERNAL AND INTERNAL PERSPECTIVES. 52nd International Scientific Conference of Daugavpils University, Daugavpils, Latvia. Retrieved from: https://files.eric.ed.gov/fulltext/ED531732.pdf 